\title{
Operative and early results of coronary artery bypass grafting in female patients in different body mass indexes
}

\author{
Hilmi Tokmakoglu
}

\begin{abstract}
Background: Female gender has been reported to be an independent risk factor for coronary artery bypass grafting (CABG) in European System for Cardiac Risk Evaluation. The effect of the body size on the CABG outcome is less clear. There is ongoing debate about obesity as a risk factor for adverse outcomes after cardiovascular procedures. The goal of this retrospective study is to evaluate the in hospital and early postoperative outcomes in severe obese, obese and normal-slightly obese female patients after CABG.

Methods: In a four year period a total of 427 female patients underwent isolated CABG under cardiopulmonary bypass. The patients were allocated into three groups according to the Body Mass Index (BMI) as follows; group 1: severe obese patients; $\mathrm{BMI}>35$, group 2: obese patients; $30 \leq \mathrm{BMI} \leq 35$, group 3: normal-slightly obese patients; BMI $<30$
\end{abstract}

Results: The patients in group 3 were older than the group 1 and group $2(65,6 \pm 8,3$ year vs $63,01 \pm 8,0$ and 63,57 $\pm 8,4$ year $p<0,05$ ). In group 1 diabetic patients were more than in group 2 and group 3 respectively (54,4\% vs $43,4 \%$ and $40 \%, p<0,05$ ). Urgent operation was more in group 1 than in group 2 and 3 respectively (37,6\% vs $17,2 \%$ and $21,2 \% p<0,05)$. The patients in group 3 had significantly greater postoperative drainage at $24 \mathrm{~h}$ compared with values in group 1 and group $2(647 \pm 142 \mathrm{ml}$ vs. $539 \pm 169 \mathrm{ml}$ and $582 \pm 133 \mathrm{ml}, \mathrm{p}<0,05)$. Mortality rate in group 1 was $0,8 \%, 0 \%$ in group 2 and 1,2\% in group 3 respectively. Wound problem has occured in 41 patients $(9,6 \%)$. The percentage of postoperative wound problems was higher in group 1 but did not show statiscially difference. Following discharge a total of $43(10,1 \%)$ patients re-hospitalized within 30 days. Rehospitalization rate was $16,1 \%$ in group $1,9,8 \%$ in group 2 and $6,5 \%$ in group 3 ( $p<0,05$ ).

Conclusion: This study may give an aspect for evaluations of the inhospital-early mortality and morbidity after CABG in female patients in different BMI. Severe obesity is not a risk factor in-hospital mortality in female patients. However, severe obese female patients appear to have more wound problems and re-hospitalization rate after CABG compared to obese and normal-slightly obese patients.

\section{Background}

Female gender has been reported to be an independent risk factor for coronary artery bypass grafting (CABG) in European System for Cardiac Risk Evaluation [1]. In comparison to male patients female patients undergoing CABG have more comorbid risk factors such as; older age, smaller body size, higher prevalance of hypertension, diabetes mellitus, unstable anjina pectoris, smaller

Correspondence: h.tokmakoglu@isnet.net.tr

Cardiovascular Surgery Department, Ozel Tekden Hastanesi KocasinanKayseri, Turkey size of coronary arteries. Numerous studies have demonstrated increased hospital mortality after CABG in female patients On the other hand studies suggest that female patients clearly benefit from CABG [2-4].

The effect of the body size on the CABG outcome is less clear. There is ongoing debate about obesity as a risk factor for adverse outcomes after cardiovascular procedures [5-7]. Some studies have documented that obesity is not a risk factor for adverse outcomes [8-10] whereas other studies have concluded that extreme obesity is a significant independent predictor for adverse outcomes after CABG [11,12]. 
The goal of this retrospective study is to evaluate the in hospital and early postoperative outcomes in severe obese, obese and non-obese female patients after CABG.

\section{Methods \\ Patients}

In a four year period a total of 427 female patients underwent isolated CABG under cardiopulmonary bypass (CPB). Patients who underwent concomitant procedures such as; valve operation, carotid endarterectomy, were excluded.

\section{Data collection and definitions}

Preoperative, intraoperative and postoperative variables and complications were collected retrospectivly from hospital database. The variables defined as follows; diabetes mellitus (DM); diet-controlled, oral therapy or insulin dependent DM, hypertension; history of hypertension necessitating medical treatment, chronic obstructive pulmonary disease; predicting of forced expiratory volume in $1 \mathrm{sec}$ or diffusion capacity less than $75 \%$ at pulmonary functional test, vascular disease; peripheral, abdominal vascular pathology or operation, rhythm; preoperative sinus rhythm, ejection fraction $\leq 40 \%$; determined with preoperative transthoracic echocardiography and named as poor ventricular function, pulmonary hypertension; pulmonary artey pressure $\geq 30 \mathrm{mmHg}$ determined with preoperative transthoracic echocardiography, creatinin level; blood creatinin level preoperatively and 1st postoperative day, thyroid disease; hypothyroidism or hyperthyroidism necessitating therapy and all patient's thyroid functions were measured preoperatively, left main coronary artery disease (LMCA); LMCA stenoses $\geq 70$, preoperative myocardial infarction (MI); history of MI before the operation, operative status; elective: stabil cardiac function and operation is more than 1 day following diagnosis, urgent; the operation that occurred within $24 \mathrm{~h}$ of coronary catheterisation because of critically vessel lesion with unstable symptoms, emergency; operation is within the hours for evolving infarction, ischemia not responding to medical therapy, cardiogenic shock or very critically LMCA and right coronary artery disease, inotrophic support and/or IABP; intraoperative and/or postoperative inotrophic - IABP support due to haemodynamic instability, perioperative myocardial infarction; a new Q wave and rise in CPK-MB \% $\geq$ $10 \%$, re-exploration; re-operation for bleeding, tamponade, neurological complications; postoperative cerebrovascular accidents and/or transient ischemic attack, pulmonary complications; re-entubation, pulmonary infection, severe athelectazia necessitating intensive fizyotherapy postoperatively, wound problems; consist in-hospital and within 30 days following discharge; sternotomy and saphenous incision problems were seperately defined as follows; sternotomy wound problems; superficial infections, deep wound-mediastinal involvement and sternal dehiscence, saphenous incision problems; wound healing problems requiring surgical debritman, mortality; all mortality during postoperative hospital stay, re-hospitalization; following discharge re-hospitalization within 30 days due to pulmonary emboli, deep venous thrombosis, plevral effusion requiring thorasentesis, heart failure, arrhytmia, severe creatinin elevation and wound problems, Body Mass Index (BMI); calculated as weight $(\mathrm{kg}) /$ height squared $(\mathrm{m} 2)$. The patients were allocated into three groups according to the BMI as follows;

Group 1: Severe obese patients; BMI $>35$

Group 2: Obese patients; $30 \leq \mathrm{BMI} \leq 35$

Group 3: Normal-slightly obese patients; BMI $<30$

\section{Surgical technique}

All patients were operated using standart CPB tecnique, aortic and two stage right atrial cannulation, systemic hypothermia (28-32 C). Internal thoracic artery and saphenous vein were harvested with conventional technique. Following cross-clamping of the aorta the heart was arrested using intermittant cold blood cardioplegia antegradely and retrogradely, continued with in every 20 min, and finally warm blood cardioplegia was administered before releasing the aortic cross-clamp. The left internal thoracic artery (LITA) was the graft of choice for left anterior descending coronary artery (LAD) in patients and saphenous vein grafts (SVG) for the other anastomosis. After distal anastomoses, proximal anastomoses were done during reperfusion with an partial aortic occluding clamp. During the CPB hematocrit levels were maintained above $20 \%$. Also in all patients efforts were made to ensure perioperative and postoperative blood glucose levels in the range of 150 to $200 \mathrm{mg} / \mathrm{dL}$. After routine closure of the chest, continuous suction $(10 \mathrm{mmHg})$ was applied to the drains, which were milked and stripped at 30-min intervals to ensure tube patency. Chest tubes were removed the following day when the drainage was less than $20 \mathrm{ml} / \mathrm{h}$ for consecutive $4 \mathrm{~h}$. All patients were extubated in the intensive care unit (ICU) after establishment of hemodynamic stability. After ICU period, regulation of blood glucose levels were done by internal medicine departmant.

\section{Statistical analysis}

Data evaluation was carried out using a computer statistical package (SPSS 15.0 for Windows, SPSS, Inc., Chicago, IL) and are expressed as means \pm SD or as frequencies or percentages. The relationships between 
independent preoperative and operative variables and postoperative outcome measures were investigated by One-way Anova test or $\chi^{2}$ test for categorical variables. A $P$ value of $<0.05$ was considered significant.

\section{Results}

Preoperative variables are listed in Table 1 . There were 125 patients in group 1, 122 patients in group 2 and 170 patients in group 3 . The mean BMI was $37,8 \pm 2,6$ in group1, 32,0 $\pm 1,3$ in group2 and $26,7 \pm 2,5$ in group3 respectively.

The patients in group 3 were older than the group 1 and group $2(65,6 \pm 8,3$ year vs $63,01 \pm 8,0$ and 63,57 \pm $8,4$ year $\mathrm{p}<0,05)$. In group 1 diabetic patients were more than in group 2 and group 3 respectively $(54,4 \%$ vs $43,4 \%$ and $40 \%, p<0,05)$. The remaining factors of hypertension, smoking, cholesterol level, the percantage of chronic obstructive pulmonary disease (COPD), peripheral vascular disease, the percantage of sinus rythm, previous MI, left main coronary artery disease (LMCA), the extension of vessel disease, mean ejection fractionpercantage of EF $\% \leq 40$, pulmonary hypertension (PHT), mean preoperative and 1 st postoperative day creatinin levels showed no statistical differences between the three groups.
Operative and early postoperative variables are listed in Table 2. Urgent operation was more in group 1 than in group 2 and 3 respectively (37,6\% vs $17,2 \%$ and $21,2 \%$ $\mathrm{p}<0,05)$. Also elective surgery was more in group 2 and 3 than in group $1(75,4 \%$ and $75,9 \%$ vs $58,4 \% \mathrm{p}<0,05)$. The other parameters; mean CABG number, percantage of LITA usage, mean aortic cross clamp time (ACC), cardiopulmonary bypass time (CPBT), percantage of inotrophic support, mean extubation and intensive care unit (ICU) time did not differ beetween the groups. The patients in group 3 had significantly greater postoperative drainage at $24 \mathrm{~h}$ compared with values in group 1 and group $2(647 \pm 142 \mathrm{ml}$ vs. $539 \pm 169 \mathrm{ml}$ and $582 \pm$ $133 \mathrm{ml}, \mathrm{p}<0,05)$. Four patients in group 3 was revised due to bleeding and/or tamponade whereas none in group 1 and 2. Also occurence of atrial fibrillation (AF), perioperative $\mathrm{MI}$, neurological and pulmonary complications did not differ between the groups. The overall hospital mortality rate was $0,7 \%$. Mortality rate in group 1 was $0,8 \%, 0 \%$ in group 2 and $1,2 \%$ in group 3 respectively. Wound problem has occured in 41 patients $(9,6 \%)$. The percentage of postoperative wound problems was higher in group 1 but did not show statiscially difference. Following discharge a total of $43(10,1 \%)$ patients re-hospitalized within 30 days due to reasons mentioned

Table 1 Preoperative variables

\begin{tabular}{|c|c|c|c|c|}
\hline Variable & Group 1 (n:125) & Group 2 (n:122) & Group 3 (n:170) & $p$-value \\
\hline Age, (year) & $63,01 \pm 8,0$ & $63,57 \pm 8,4$ & $65,6 \pm 8,3$ & 0,015 \\
\hline $\mathrm{BMl}$ & $37,8 \pm 2,6$ & $32,0 \pm 1,3$ & $26,7 \pm 2,5$ & \\
\hline $\mathrm{DM}$ & $54,4 \%$ & $43,4 \%$ & $40 \%$ & 0,043 \\
\hline Hypertension & $65,6 \%$ & $62,3 \%$ & $57,6 \%$ & 0,3 \\
\hline Smoking & $7,2 \%$ & $11,5 \%$ & $7,6 \%$ & 0,4 \\
\hline Cholesterol(mg/dl) & $211,2 \pm 47,3$ & $209 \pm 44,5$ & $208,5 \pm 50,2$ & 0,8 \\
\hline COPD & $24,8 \%$ & $13,9 \%$ & $21,8 \%$ & 0,08 \\
\hline PVD & $4 \%$ & $3,3 \%$ & $4,7 \%$ & 0,8 \\
\hline Sinus rythm & $99,2 \%$ & $99,1 \%$ & $98,8 \%$ & 0,5 \\
\hline \multicolumn{5}{|l|}{ Thyroid disease } \\
\hline Hypothyroidism & $8(6,4 \%)$ & $6(4,9 \%)$ & $10(5,9 \%)$ & 0,8 \\
\hline Hyperthyroidism & $3(2,4 \%)$ & $4(3,3 \%)$ & $6(3,5 \%)$ & 0,8 \\
\hline PreMl & $29,6 \%$ & $18,2 \%$ & $22,4 \%$ & 0,09 \\
\hline \multicolumn{5}{|l|}{ Vessel disease } \\
\hline 1 vessel & $12 \%$ & $9,8 \%$ & $11,8 \%$ & 0,98 \\
\hline 2 vessel & $29,6 \%$ & $30,3 \%$ & $29,4 \%$ & 0,98 \\
\hline 3 vessel & $58,4 \%$ & $59,8 \%$ & $58,8 \%$ & 0,98 \\
\hline$\angle M C A$ & $8,8 \%$ & $8,2 \%$ & $6,5 \%$ & 0,7 \\
\hline $\mathrm{EF} \%$, mean $\pm \mathrm{SD}$ & $54,3 \pm 10,8$ & $55,9 \pm 9,6$ & $56,5 \pm 10,3$ & 0,17 \\
\hline $\mathrm{EF} \% \leq 40$ & $16,8 \%$ & $9,8 \%$ & $10,6 \%$ & 0,17 \\
\hline PHT $(m m H g, \%)$ & $16 \%$ & $14,8 \%$ & 20,6 & 0,37 \\
\hline Creatinin1 (mg/dl) & $0,89 \pm 0,19$ & $0,90 \pm 0,15$ & $0,87 \pm 0,17$ & 0,26 \\
\hline Creatinin 2 (mg/dl) & $1,1 \pm 1,2$ & $1,0 \pm 0,3$ & $0,95 \pm 0,28$ & 0,15 \\
\hline
\end{tabular}

COPD; chronic obstructive pulmonary disease, PVD; peripheral vascular disease, PreMl; preoperative MI, PHT; pllmonary hypertension, Creatinin1; preoperatively, 2; postoperatively creatinin level 
Table 2 Operative and early postoperative variables

\begin{tabular}{|c|c|c|c|c|}
\hline Variable & Group 1 & Group 2 & Group 3 & P-value \\
\hline \multicolumn{5}{|l|}{ Operative status \% } \\
\hline Emergency & 5,6 & 6,6 & 3,5 & 0,4 \\
\hline Urgent & 37,6 & 17,6 & 21,2 & 0,0001 \\
\hline Elective & 58,4 & 75,8 & 75,9 & 0,002 \\
\hline CABG $(n)$ & $2,98 \pm 0,89$ & $2,98 \pm 0,78$ & $2,95 \pm 0,79$ & 0,93 \\
\hline LITA usage\% & 89,6 & 90,2 & 89,7 & 0,3 \\
\hline ACC (min) & $38,3 \pm 12,0$ & $37,8 \pm 10,1$ & $37,7 \pm 10,5$ & 0,71 \\
\hline CPBT (min) & $57,6 \pm 16,9$ & $56,9 \pm 13,6$ & $57,0 \pm 14,6$ & 0,82 \\
\hline Inotrophic support \% & 20 & 12,3 & 18,9 & 0,21 \\
\hline Extubation time(hour) & $11,7 \pm 3,4$ & $11,7 \pm 3,5$ & $12,0 \pm 4,4$ & 0,62 \\
\hline ICU time(hour) & $25,7 \pm 3,6$ & $27,7 \pm 24,3$ & $26,7 \pm 16,0$ & 0,54 \\
\hline Drenaige (ml) & $539 \pm 169$ & $582 \pm 133$ & $647 \pm 142$ & 0,0001 \\
\hline Revision & 0 & 0 & $4(2,6 \%)$ & 0,053 \\
\hline AF \% & 24 & 20,5 & 20,0 & 0,68 \\
\hline Perioperative Ml & $3(2,4 \%)$ & $3(2,5 \%)$ & $5(2,9 \%)$ & 0,9 \\
\hline NC \% & 0,8 & 0 & 0,6 & 0,63 \\
\hline Pulmonary compl.\% & 4,8 & 1,6 & 2,4 & 0,41 \\
\hline Wound problems & $16(12,8 \%)$ & $11(9 \%)$ & $14(8,2 \%)$ & 0,40 \\
\hline \multicolumn{5}{|l|}{ Sternotomy } \\
\hline Superficial & $4(3,2 \%)$ & $3(2,5 \%)$ & $4(2,4 \%)$ & 0,89 \\
\hline Deep & $2(1,6 \%)$ & $1(0,8 \%)$ & $2(1,2 \%)$ & 0,85 \\
\hline Dehisence & $4(3,2 \%)$ & $3(2,5 \%)$ & $3(1,8 \%)$ & 0,72 \\
\hline Saphenous & $6(4,8 \%)$ & $4(3,3 \%)$ & $5(2,9 \%)$ & 0,67 \\
\hline Mortality & $1(0,8 \%)$ & 0 & $2(1,2 \%)$ & 0,49 \\
\hline Re-hospitalization & $20(16,1 \%)$ & $12(9,8 \%)$ & $11(6,5 \%)$ & 0,02 \\
\hline DVT & 3 & 0 & 0 & \\
\hline$D V T+P E$ & 1 & 1 & 0 & \\
\hline Plevral effusion & 2 & 1 & 3 & \\
\hline Heart failure & 2 & 1 & 0 & \\
\hline Arrythmia & 2 & 2 & 1 & \\
\hline Creatinin elevation & 2 & 2 & 1 & \\
\hline Wound problems & 8 & 5 & 6 & \\
\hline
\end{tabular}

ACC; aortic cross clamp time, CPBT; cardiopulmonary bypass time, ICU; intensive care unit, AF; atrial fibrillation, NC; neurological complication, DVT; deep venos thyrombosis, PE; pulmonary emboli

above. Re-hospitalization rate was $16,1 \%$ in group $1,9,8 \%$ in group 2 and $6,5 \%$ in group $3(\mathrm{p}<0,05)$.

\section{Discussion}

Cardiovascular disease is leading cause of morbidity and mortality for women in developed and developing countries. There is considerable evidence that female gender carry a higher CABG mortality when compared with the male patients [13-15]. On the other hand obesity is considered to be a major risk factor in patients undergoing CABG. With the increasing of BMI also comorbidty increases [16,17]. There are major differences in the risk profile of female patients compared with the profile of male patients $[18,19]$. The great majority of studies show that diabetes is $40 \%$ to $50 \%$ more common in female patients than male patients undergoing CABG
[20,21]. In this study diabetes is found to be $45,3 \%$ in totally whereas $54,4 \%$ in severe obese patients. It is wellknown that there is a clear association of diabetes with adverse postoperative outcome in surgical patients. Despite the usage of prophylactic antibiotics, sternal wound infections are associated high mortality and morbidity. In our severe obese patients sternal superficial infections and sternal dehisence were more common but not statistically significant than the other groups. Some studies were emphasised that hyperglycemia in the first 2 postoperative days is the single most important predictor of mediastinitis after cardiac surgery and blood glucose level must be maintained below $200 \mathrm{mg} /$ $\mathrm{dL}[22,23]$. As mentioned before in our patients special efforts were made to ensure perioperative and postoperative blood glucose levels in the range of 150 to 200 
$\mathrm{mg} / \mathrm{dL}$ with the using of continuous intravenous insulin infusions.

Hypothyroidism is associated with impaired ventricular contractility and in female patients there is a higher incidence of hypothyroidism undergoing CABG [24]. In the study of Zindrou and colleagues they found a high mortality rate $(16,7 \%)$ in female patients requiring thyroid replacement therapy whereas not in male patients [25]. In our clinic all patient's thyroid functions were measured preoperatively and hypothyroidic patients were maintained in a euthyroid state before the operation. In non-elective status patients therapy was begun before the operation and contiuned following operation.

The use of at least one LITA confers both in-hospital and long-term improvement in CABG mortality $[26,27]$. However usage of LITA as a conduit in female patients is only $60 \%-75 \%$ of cases $[28,29]$. This is significantly less than LITA usage in male patients. Actually there is no objective reason to use the LITA less ferquently in females than the males. Perhaps the presence of a soft friable sternum that predisposes sternal dehisence is a valid reason to avoid use of LITA [30]. In the study of Aldea and colleagues LITA was used in 91\% of female patients and found no gender differences in operative mortality [31].

In most series there is a higher rate of non-elective CABG in female patients [28,31]. Likewise in our study the rate of non-elective surgery was $29,2 \%$ in all patients whereas statiscially higher in group 1 than the other groups. Also in other studies it was emphasised that use of LITA is safe when urgent and emergency operations are being performed [32,33]. In our study use of LITA as a conduit was found $89,6 \%$ in severe obese group even percentage of urgent surgery was high.

Some studies found a significant reduction for the risk of postoperative bleeding in obese patients [34,35]. Likewise in our study the amount of bleeding and reexploration rate was less in obese grups than the nonobese grup.

Atrial fibrillation (AF) is a frequent event after CABG with an incidence of $15-40 \%$. It may result in hemodynamic compromise during the postoperative period. There are some reports saying AF are seen in high BMI score patients $[36,37]$. In our patients there was no significant difference between the three groups

We did not find a significant difference ICU time, creatinin levels, neurological complications and mortality rates between the three groups.

Obesity alters the pulmonary function leading to an increase in functional residual capacity, and a decrease in vital capacity and maximum voluntary ventilation [38]. In addition, anaesthetic drugs that are revealed from the fat tissue may prolong the entubation time. Also patients with low BMI have remarkable haemodilution, fall in the oncotic pressure during $\mathrm{CPB}$ and this may lead excess fluid extravasation [39]. In this study we did not find a significant difference for extubation time between the groups. Hovewer postoperatively pulmonary complication was more common in group1 but showed no statiscially difference.

Readmission following discharge is an important adverse outcome of CABG surgery. Hannan El et al. examined the frequency and causes of CABG surgery readmissions and in their study they found $15,3 \%$ readmisions within 30 days following discharge. Also they found female gender is a risk factor of readmission after CABG [40]. In our study a total of $43(10,1 \%$, mostly in group1) patients readmitted and re-hospitalized following discharge.

\section{Limitations of the study}

This study was done on a retrospective series from a single institution and also gives only in-hospital and early postoperative period outcomes. Further complementary studies with higher number of patients and including early, mid-term, long-term results in contemporary methods are warranted.

\section{Conclusion}

This study may give an aspect for evaluations of the inhospital-early mortality and morbidity after CABG in female patients in different BMI. Female gender and also severe obesity is not a risk factor in-hospital mortality. However, severe obese female patients appear to have more wound problems and re-hospitalization rate after CABG compared to obese and non-obese patients.

\section{Authors' contributions}

HT: Performed operations, wrote manuscript.

Author read and approved the final manuscript.

\section{Competing interests}

The authors declare that they have no competing interests.

Received: 29 September 2010 Accepted: 26 November 2010 Published: 26 November 2010

\section{References}

1. Roques F, Nashef SA, Michel P, Gauducheau E, de Vincentiis C, Baudet E, et al: Risk factors and outcome in European cardiac surgery: analysis of the EuroSCORE multinational database of 19030 patients. Eur $J$ Cardiothoracic Surg 1999, 15:816-822.

2. Loop FD, Golding LR, MacMillan JP, Cosgrove DM, Lytle BW, Sheldon WC: Coronary artery surgery in women compared with men: analysis of risk and long term results. J Am Coll Cardiol 1983, 1:383-390.

3. Gardner TJ, Horneffer PJ, Gott VL, Watkins L Jr, Baumgartner WA, Borkon AM, et al: Coronary artery bypass grafting in women. Ann Surg 1985, 201:780-784.

4. Herlitz J, Brandrup-Wognsen G, Karlson BW, Sjoland H, Karlsson T, Caidahl K, et al: Mortality, risk indicators of death, mode of death and symptoms of angina pectoris during 5 years aftercoronary artery bypass grafting in men and women. J Intern Med 2000, 247:500-506.

5. Jin R, Grunkemeier GL, Furnary AP, Handy JR Jr: Is obesity a risk factor for mortality in coronary artery bypass surgery? Circulation 2005, 111:3359-3365. 
6. Pan W, Hindler K, Lee V, Vaughn W, Collard CD: Obesity in diabetic patients undergoing coronary artery bypass graft surgery is associated with increased postoperative morbidity. Anesthesiology 2006, 104:441-7.

7. Prabhakar G, Haan CK, Peterson ED, Coombs LP, Cruzzavala JL, Murray GF: The risks of moderate and extreme obesity for coronary artery bypass grafting outcomes: A study from The Society of Thoracic Surgeons' Database. Ann Thorac Surg 2002, 74:1125-1131.

8. Moulton MJ, Creswell LL, Mackey ME, Cox $\lrcorner$, Rosenbloom M: Obesity is not a risk factor for significant adverse outcomes after cardiac surgery. Circulation 1996, 95(Suppl 9):1187-1192.

9. Fisher LD, Kennedy JW, Davis KB, Maynard C, Fritz JK, Kaiser G, Myers WO: Association of sex, physical size, and operative mortality after coronary artery bypass in the coronary artery study (CASS). J Thorac CardiovasC Surg 1982, 84:334-341.

10. Prasad US, Walker WS, Sang CTM, Campenella C, Cameron EWJ: Influence of obesity on the early and long term results of surgery for coronary artery disease. Eur J Cardiothorac Surg 1991, 5:67-73.

11. Prabhakar G, Haan CK, Peterson ED, Coombs LP, Cruzzavala JL, Murray GF: The risks of moderate and extreme obesity for coronary artery bypass grafting outcomes: A study from The Society of Thoracic Surgeons' Database. Ann Thorac Surg 2002, 74:1125-1131.

12. Habib RH, Zacharias A, Schwann TA, et al: Effects of obesity and small body size on operative and long-term outcomes of coronary artery bypass surgery: a propensity-matched analysis. Ann Thorac Surg 2005, 79:1976-1986

13. Carey JS, Cukingnan RA, Singer LKM: Health status after myocardial revascularization: inferior status in women. Ann Thorac Surg 1995, 59:112-1117.

14. Edwards FH, Carey JS, Grover FL, Bero JW, Hartz RS: Impact of gender on coronary bypass operative mortality. Ann Thorac Surg 1998, 66:125-131.

15. Hammar N, Sandberg E, Larsen FF, Ivert T: Comparison of early and late mortality in men and women after isolated coronary artery bypass graft surgery in Stockholm, Sweden1980 to 1989. J Am Coll Cardiol 1997, 29:659-664.

16. Health counsil of the Netherlands: Overweight and obesity. The Hague: Health counsil of the Netherlands; 2003, Publication no. 2003/07.

17. Ray CS, Sue DY, Bray G, Hansen JE, Wasserman K: Effects of obesity on respiratory function. Am Rev Respir Dis 1983, 128:501-506.

18. Zitser-Gurevich Y, Simchen E, Galai N, Mandel M: Effect of perioperative complications on excess mortality among women after coronary bypass. In J Thorac Cardiovasc Surg. Volume 123. The Israeli Coronary Bypass Graft study(ISCAB); 2002:517-524.

19. Koch CG, Khandwala F, Nussmeier N, Blackstone EH: Gender profiling in coronary artery bypass grafting. J Thorac Cardiovasc Surg 2003, 126:2044-2051.

20. Vaccarino V, Abramson JL, Veledar E, Weintraub WS: Sex differences in hospital mortality after coronary artery bypass surgery. Circulation 2002, 105:1176-1181.

21. Woods SE, Noble G, Smith JM, Hasselfeld K: The influence of gender in patients undergoing coronary artery bypass graft surgery: an eight year prospective hospitalized cohort study. J Am Coll Surg 2003, 196:428-434.

22. Furnary AP, Zerr KJ, Grunkemeier G, Starr AS: Continuous intravenous insulin infusion reduces the incidence of deep sternal wound infection in diabetic patients after cardiac surgical procedures. Ann Thorac Surg 1999, 67:352-360.

23. Zerr KJ, Furnary AP, Grunkemeier GL, et al: Glucose control lowers the risk of wound infection in diabetics after open heart operations. Ann Thorac Surg 1997, 63:356-361.

24. Eagle KA, Guyton RA, Davidoff R, et al: ACC/AHA 2004 guideline update for coronary artery bypass graft surgery: a report of the American College of Cardiology/American Heart Association Task Force on Practice Guidelines (Committee to Update the 1999 Guidelines for Coronary Artery Bypass Graft Surgery). J Am Coll Cardiol 2004, 44:1146-54.

25. Zindrou D, Taylor KM, Bagger JP: Excess coronary artery bypass mortality among women with hypothyroidism. Ann Thorac Surg 2002, 74:2121-2125.

26. Edwards FH, Clark RE, Schwartz M: The impact of internal mammary artery conduits on operative mortality in coronary revascularization. Ann Thorac Surg 1994, 57:27-32.

27. Leavitt BJ, O'Connor GT, Olmstead EM, et al: Use of the internal mammary artery graft and in-hospital mortality associated with coronary artery bypass grafting. Circulation 1998, 98:130.
28. Abramov D, Tamariz MG, Sever JY, et al: The influence of gender on the outcome of coronary artery bypass surgery. Ann Thorac Surg 2000, 70:800-806.

29. Lawton JS, Brister SJ, Petro KR, Dullum M: Surgical revascularization in women: unique intraoperative factors and considerations. J Thorac Cardiovasc Surg 2003, 126:936-938.

30. Mickleborough LL, Takagi Y, Mariyama H, Sun Z, Mohamed S: Is sex a factor in determining operative risk for aortocoronary bypass surgery? Circulation 1995, 92(supp 1):1180-1184.

31. Aldea GS, Gaudiani JM, Shapira OM, et al: Effect of gender on postoperative outcomes and hospital stays after coronary artery bypass grafting. Ann Thorac Surg 1999, 67:1097-1103.

32. Cohn LH: Use of the internal mammary artery graft and in-hospital mortality and other adverse outcomes associated with coronary artery bypass surgery. Circulation 2001, 103:483-484.

33. Leavitt BJ, O'Connor GT, Olmstead EM, et al: Use of the internal mammary artery graft and in-hospital mortality and other adverse outcomes associated with coronary artery bypass surgery. Circulation 2001, 103:507-512

34. Birkmeyer NJO, Charlesworth DC, Hernandez F, Leavitt BJ, Marrin CA, Morton JR, Olmstead EM, O'Connor GT: Obesity and risk of adverse outcomes associated with coronary artery bypass surgery. Circulation 1998, 97:1689-1694.

35. Engelman DT, Adams DH, Byrne JG, Aranki SF, Collins JJ, Couper GS, Allred EN, Cohn LH, Rizzo RJ: Impact of body mass index and albumin on morbidity and mortality after cardia surgery. J Thorac Cardiovasc Surg 1999, 118:867-873.

36. Moulton MJ, Creswell LL, Mackey ME, Cox $J$, Rosenbloom M: Obesity is not a risk factor for significant adverse outcomes after cardiac surgery. Circulation 1996, 95(Suppl 9):1187-1192.

37. Koshal A, Hendry P, Raman SV, Keon WJ: Should obese patients not undergo coronary artery surgery? Can J Surg 1985, 28:331-334

38. Jenkins SC, Moxham J: The effects of mild obesity on lung function. Respir Med 1991, 85:309-311.

39. Reeves BC, Ascione R, Chamberlain MH, Angelini GD: Effect of body mass index on early outcomes in patients undergoing coronary artery bypass surgery. J Am Coll Cardiol 2003, 42:668-676.

40. Hannan EL, Racz MJ, Walford G, et al: Predictors of readmission for complications of coronary artery bypass surgery. JAMA 2003, 290:773-780.

doi:10.1186/1749-8090-5-119

Cite this article as: Tokmakoglu: Operative and early results of coronary artery bypass grafting in female patients in different body mass indexes. Journal of Cardiothoracic Surgery 2010 5:119.

\section{Submit your next manuscript to BioMed Central and take full advantage of:}

- Convenient online submission

- Thorough peer review

- No space constraints or color figure charges

- Immediate publication on acceptance

- Inclusion in PubMed, CAS, Scopus and Google Scholar

- Research which is freely available for redistribution 